\title{
Histology of Testes
}

\author{
Dr.L.L.Sailaja ${ }^{1}$ Dr.A.Vasanthi ${ }^{2}$, \\ I'Assistant Professor, Department Of Anatomy, Andhra Medical College, Visakhapatnam.) \\ ${ }^{2}$ (Associate Professor, Department Of Anatomy, Rangaraya Medical College, Kakinada)
}

\begin{abstract}
Introduction: Testes is male gonad. Its histological features and its complete development is necessary for reproduction . variations or any changes are associated with male infertility.

Aim \& Object: The present study is to establish age related changes in histology of testes. The present study is to identify significant histological changes as advances.

Materials and methods 15 to 70 years were collected from cadavers in anatomy department. Slides were prepared with haemotoxylin and eosin stains and examined. 10\% formalin was used for storage. Compound microscope is used for slides examination.

Results: Complete maturity of testes had occurred at the age between 14 to 20 years. Marked reduction of parenchyma had occurred after 45 years accociated with increased connective tissue. Details will be discussed at the conference.

Conclusion: Maximum development is associated with puberty to 20 years and it is stable up to 40 years.

Keywords. Testes, development, puberty.

\section{Introduction}

Histology of testes is important for under standing the problems of infertility and sex development and growth. Studies had indicated that testicular dysfunctions are associated with histological variations .The present study focused on estabilishing it. The comparision has been done on histological pattern of prepubertal, pubertal ,or adult, and senile or old age to know the difference of histology of testes.
\end{abstract}

\section{Materials And Methods}

50 testes of male cadavers are collected from Anatomy department. They are categorized into prepubertal, pubertal and senile depending on their age. From 5 years to 15 years as prepubertal, from 15 to 50 years as adult and from 55 years onwards as old age. Histology slides were prepared and stained with haemotaxilin and eosin stains. Histological findings were observed. This study is conducted during 2013 to 2016 years.
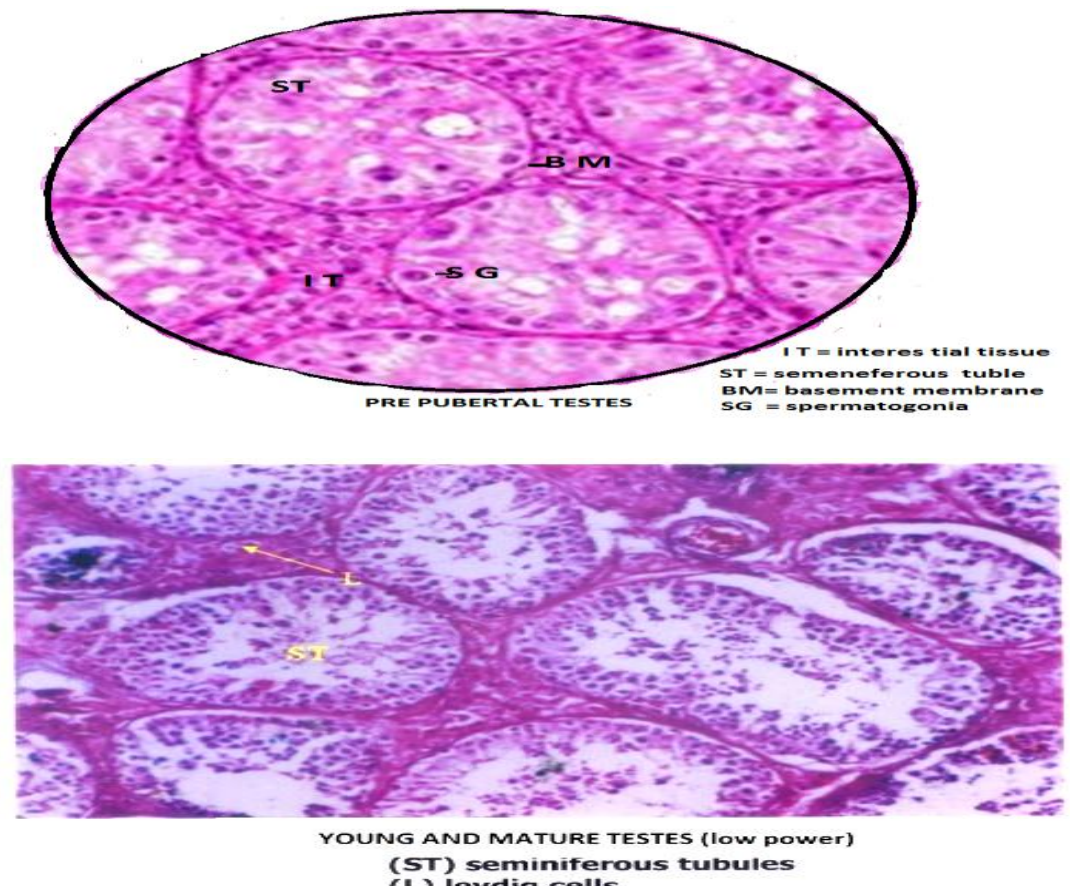

(LT) seminifero 


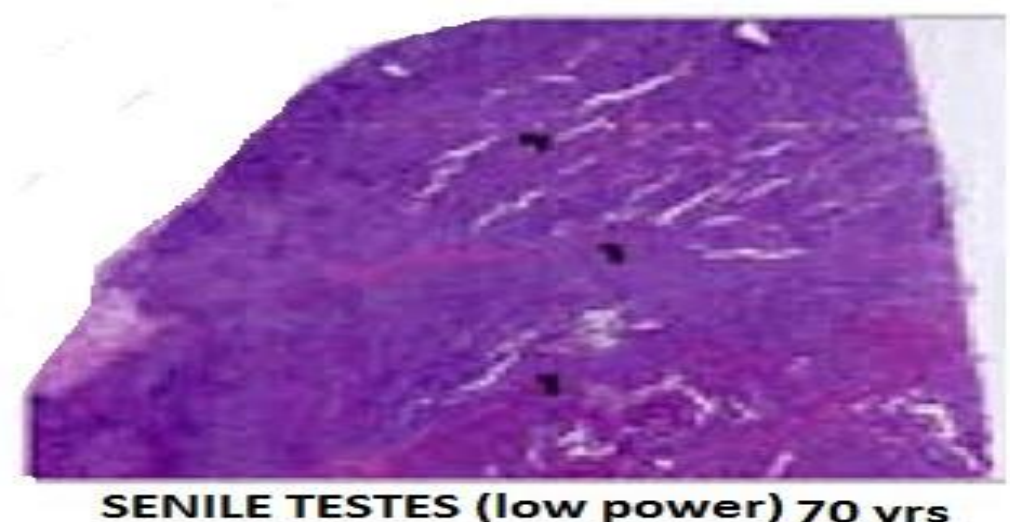

\section{Observations And Results}

The development of testes is found characteristic changes between birth to old And the changes were observed and found as prepubertal, pubertal, young and mature and old age senile. The age related changes are easily demonstrated and constant in lower animal dog 6 . In human transitional atrophic changes were observed in semineferous tubels particularly more marked after 50 years of age. The results are divided into three parts prepubertal, pubertal or adult and old age. In pre pubertal period semineferous tubels are small and basement membrane is thin. In pubertal period or adult testes the semineferous tubels are more and the percentage of spermatids and semineferous tubels are $90 \%$ same as compared with previous studies 7 . As age advaces towards senility the lesions in basement membrane of semineferous tubels are found, pigmentation in ley dig cells is found. The percentage of semine ferous tubels are decreased. The appearance of speramatids is decreased. And the ratio between semeniferous tubels and spermatids had reached to $20 \%$. In the 70 years of age, indicating the decline of male fertility further studies in food habits and occupation and genetic pattern and vascular pattern may reveal the definite cause of declining in male fertility which will help the andrologists.

\section{Discussion}

The testes development depends on the testes determining factor of chromosome of S.R.Y gene 4 beta catenin machinery. It is involved in testicular embryonic angiogenesis 5 . The normal histological features of human testes are given in standard text books of histology. The present study is done by low magnification 2 . the testes is covered by capsule which sends septa by dividing the testes in to lobules. The lobules contain semineferous tubels and clusters of interstitial cells of leydig are observed in between seminiferous tubrale . Testis is covered by three layers

A) Tunica vaginalis

B) Tunica albugenia

C) Tunica vasculosa

Tunica albugenia a dense fibrous capsule, from it's anterior surface sends septa and extend and divide the testes into 250 to 300 lobules ( test book of histology Dr. Subadra devi). Tunica vasculosa is a vascular membrane lining the individual lobule of testes. Each lobule of the tests contains 2-4 tightly coiled semineferous tubels form exocrine part of testis, Endocrine part of the testis is the leydig cells present in between semineferous tubels. Semineferous tubels are the structural and functional units of the testes. These semineferous tubels are covered by basement membrane and lined internally by complex stratified epithelium composed of two types of cells they are speromatogenic cells snd supporting cells sertoli 3 .

\section{Conclusion}

The present study resembles the previous studies reported in literature. The present study helps to evaluate the fertility context of male.

\section{References}

[1]. Inderbir s ingh's text book of human histology jaypee the health publishers , new delhi chapter $19^{\text {th }} 7^{\text {th }}$ edition 2014 , page no 322 329.

[2]. Lutz slomianka blue histology-male reproductive system ,06/08/2009

[3]. V.Subhadra devi Basic Histolgy a color atlas, jaypee brothers medical publishers (p) ltd New Delhi, chapter 16, first edition 2016 page 234-236.

[4]. Mark hill unsw embryology , testis development, wediawiki publishers , 14 june 2016

[5]. Maria Caruso, Francesca Ferranti, katia corano scheri, gabriella dobrowolny, Fabio ciccarone, paola grammatico, angela catizone, giulia ricci. One 2015, 10(4) e0124213. 
[6]. A.B.Lawrence weld smith, senile changes of the testis and prostate in dogs,pathological laboratories of the Harvard Medical School, Boston. April,30 1919.

[7]. Nobuaki sasano, sadatoshi ichijo, vascular patterns of the human testis with special reference to its senile changes, the Tohoku journal of experimental medicine, vol.99 (1969) no.3 P 269-280.

[8]. Yu SS, O.Takenaka, molecular cloning, structure, and testis-specific expression of MFSJ1, a member of the DNAJ protein family, in the Japanese monkey (Macaca fuscata). Biochem biophys res commun. 2003 Feb 7;301(2):443-9

[9]. S.shishito sadatoshi ichijo, vascular patterns of the human testis with special reference to its senile changes, the Tohoku journal of experimental medicine, vol.99 (1969) no.3 P 269-280.

[10]. E.taberner, pubertal age based on testicular and epididymal histology in Gottingen minipigs , the riogenology2015 07,030. 